\title{
Aborto Legal: Elementos Sociohistóricos Para o Estudo do Aborto Previsto por Lei no Brasil ${ }^{(*)}$
}

\author{
ABORTION “IN DUE FORM”: SOCIOHISTORICAL ELEMENTS \\ FOR THE STUDY OF LEGALABORTION IN BRAZIL
}

Matthieu de Castelbajac ${ }^{(* *)}$

\begin{abstract}
RESUMO
O Brasil é um dos raros países, com legislações restritivas sobre o aborto, a ter implementado serviços hospitalares permanentes, ainda que pouco numerosos, para acolher demandas de abortos previstos por lei. Como preliminar deste estudo sobre o processo desenvolvido nos últimos 20 anos, que estendeu o acesso lícito a aborto seguro nos casos previstos por lei, pode ser útil, — especialmente em tempo de controvérsias, — trazer um esclarecimento sociohistórico sobre a formação do aborto não-punível no Brasil. Trata-se, em particular, de descrever os traços que desenham o "aborto legal". Sob este título, designamos as exigências jurídicas, técnicas e morais que condicionam a realização conveniente deste procedimento delicado.
\end{abstract}

\section{Palavras-chave}

Aborto; Direito; Sociologia.

(*) Agradeço a Rachelle Balbinot que releu este trabalho e nos ajudou nas várias fases de sua redação com críticas e indicações sempre precisas. O presente artigo resultou de uma pesquisa etnográfica no Rio de Janeiro e em São Paulo, com entrevistas com profissionais da saúde integrantes de serviços de aborto previsto por lei e de levantamentos bibliográficos feitos durante um estágio no Centro de Estudos e Pesquisa de Direito Sanitário (CEPEDISA). Para um estudo mais completo do referido processo, sugerimos a leitura de nossa dissertação, utilizada como base deste artigo. CASTELBAJAC, Matthieu de. Se détacher sans heurts: étude des dispositifs d'interruption légale de grossesse dans le Brésil contemporain. 2008. Dissertação (Mestrado) — Institut d'Études Politiques de Paris, École Doctorale de Sciences Po, 2008.

${ }^{(* *}$ Groupe de Sociologie Politique et Morale - École des Hautes Études en Sciences Sociales. E-mail : $<$ matthieu.decastelbajac@ gmail.com>. Recebido em 25.5.09. Aprovado em 20.7.09. 


\begin{abstract}
Brazil is one of the few countries with restrictive abortion laws to have implemented permanent, albeit scant, hospital services, in order to address demands of abortion due to the law. As a preliminary to this study about the process carried out over the last 20 years, which has extended access to safe abortion in conditions provided by law, it might be useful to offer some sociohistorical insights on the formation of non-criminal abortion in Brazil. To this purpose, we describe the scenery of the "abortion in due form". Under this label, we group the juridical, technical and moral requirements conditioning the realization of this procedure.
\end{abstract}

\title{
Keywords
}

Abortion; Law; Sociology.

\section{INTRODUÇÃO}

O que constitui, no Brasil contemporâneo, um "aborto legal"? Em primeiro lugar, o que é aborto? Após longos anos de debates, houve uma certa uniformização das definições jurídicas sobre o aborto entre juristas brasileiros. Atualmente, a interrupção intencional da gravidez, de modo a impedir a geração, é considerada, para todos os efeitos, como aborto.(1) No entanto, não são juristas que devem praticar o aborto, quando a lei o permitir. Os ginecologistas e obstetras, a quem essa missão cabe, julgam da permissibilidade do aborto segundo outros critérios. Sabem, desde a faculdade de medicina, que um abortamento é a explusão do produto da concepção, antes deste ter alcançado o limiar da viabilidade. Segundo uma norma médica internacional, quando houver expulsão do feto depois de 20 semanas de gestação, não se fala mais de aborto, mas de "parto prematuro". ${ }^{(2)}$

Estas diferenças lembram que fazer um aborto, por ser uma ação, significa ter que fazer com critérios de exigência variáveis. O problema pertinente para nosso trabalho, em consequência, não é que a descrição de tal ação admitiria "pontos de vista" concorrentes ou significados relativos e plurais, - o que não se debate - mas que sua realização pragmática, na situação concreta, é dependente de pontos de referência específicos. ${ }^{(3)}$ Es-

(1) Conforme Mirabete, "O aborto é a interrupção da gravidez com a morte do produto da concepção." MIRABETE, Julio Fabrini. Manual de direito penal: parte especial. São Paulo: Atlas, 2003. p. 93.

(2) FAUNDES, Aníbal; BAZELATTO, José. O drama do aborto: em busca de um consenso. Campinas: Komedi, 2004. p. 49.

(3) Cabe a Luc Boltanski o merito de ter deslocado o olhar sobre o aborto enquanto desempenho relevante de uma sociologia pragmática. BOLTANSKI, Luc; THEVENOT, Laurent. De la justification: les économies de la grandeur. Paris: Gallimard, 1991. p.60 et seq. 
tes pontos sinalizam o itinerário administrativo da candidata ao aborto previsto por lei, como também orientam o gesto do cirurgião que vai praticá-lo. São as marcas que apoiam a realização de uma "ação que convém" à situação. ${ }^{(4)}$ Ou seja, delimitam as figuras conformadas às exigências de um engajamento ajustado numa circunstância sobremaneira formalizada da vida social, a realização de um aborto previsto por lei.

Para esclarecer a configuração contemporânea do aborto não punível, precisamos identificar aqueles pontos de referência e de apoio, colocados em cada etapa do processo de acesso ao aborto legal por um longo trabalho de formalização jurídica. Não sendo juristas, não pretendemos tratar deste trabalho sob seu aspecto mais especificamente jurídico. Interessamo-nos apenas na operação de formalização cumprida pelo Direito. Tal operação se aproxima sensivelmente do trabalho sociológico. ${ }^{(5)}$ Em particular, destacamos três grandes elaborações formais. Da primeira, foram extraídas as categorias antitéticas do aborto lícito e do aborto punível. Na segunda, o julgamento sobre aborto vem se centralizando sobre uma figura feminina voluntária, mas sofredora. À última operação, correspondem os três preceitos permissivos chamados pelos juristas de "hipóteses" do aborto legal.

\section{ABORTO LÍ́CITO E ABORTO CRIMINOSO}

Existe na literatura especializada sobre aborto uma "hipótese repressiva"(6), segundo a qual, toda a história do aborto poderia se resumir à história da sua repressão, enquanto o direito à interrupção da gravidez seria uma invenção moderna. Esta divisão entre um passado repressivo e um futuro libertador diz respeito à grande narrativa emancipadora. Indica um horizonte de expectativa para fazer justiça tanto às aspirações presentes como à rememoração das situações passadas. Sem recusar este horizonte, parece-nos, contudo, que seria mais útil servimo-nos de uma compreensão menos redutora das sucessivas formalizações jurídicas do aborto. Levando-as a sério,

(4) Laurent Thévenot, na continuidade do seu trabalho com Luc Boltanski sobre o julgamento público (BOLTANSKI, Luc; THEVENOT, Laurent. op. cit.), desenvolveu uma metodologia original centrada no julgamento sobre a "ação-que-convém", isto é, sobre a integração da ação em determinados formatos de julgamento comum. THEVENOT, Laurent. L'action au pluriel: Sociologie des régimes d'engagement. Paris: La Découverte, 2006. Para uma apresentação em português da sociologia desenvolvida por Laurent Thévenot e o grupo de pesquisadores que trabalham com ele: MOTA, Fabio Reis. Deslocamentos, movimentos e engajamentos: as formas plurais da ação humana na perspectiva de Laurent Thévenot. Revista Antropolítica, Niterói, n. 23, 2008.

(5) THEVENOT, Laurent. op. cit., p.157-181.

(6) Expressão cunhada por Michel Foucault, para descrever as teorias que consideram a ação do poder sobre a sexualidade como essencialmente limitativa e negativa. Ao contrário, o filósofo chamou a atenção sobre os efeitos produtivos e incitativos do poder, em relação à constituição do sujeito moderno. FOUCAULT, Michel. Histoire de la sexualité l: la volonté de savoir. Paris: Gallimard, 1976. p. 18 et seq. 
chegamos a uma conclusão menos previsível. Não pertencendo a duas temporalidades diferentes, o aborto criminoso e o aborto lícito se formaram simetricamente, segundo critérios correspondentes, e que podem ser estilizados, de forma ideal-típica, em distintos dispositivos, cada um organizando a diferença entre situações toleradas e situações puníveis.

\section{Um dispositivo doméstico}

As Ordenações Filipinas regem a sociedade brasileira durante parte do período colonial, pelo menos a partir da consolidação da administração da justiça colonial, no início do século XVII. Deve-se observar que o aborto não figura nas Ordenações como delito. Todavia, é motivo de investigação para os quadrilheiros, isto é, um tipo de polícia de costumes, composta de homens de boa reputação, nomeados em cada paróquia. Duas práticas suspeitas são destacadas. É mandado aos quadrilheiros vigiar tanto "as mulheres que têm infamadas de fazerem mover outras", (7) como aquelas que dissimulam a gravidez. Pois, há presunção, neste caso, de aborto, infanticídio ou abandono da criança. Não há delito nenhum, propriamente dito, num caso ou no outro. Não há interdição expressa, nem punição prevista, para atender a estas condutas. ${ }^{(8)}$ As autoridades têm interesse nelas apenas porque traem a provável dissimulação de um adultério, sendo a missão geral dos quadriIheiros derrubar as relações inconfessáveis que são trazidas à notoriedade pública. Não é o aborto por si mesmo, mas o segredo acerca do aborto que o Estado combate em nome dos bons costumes. Assim, o aborto não constitui um delito, mas o sinal de uma conduta faltosa. Não é proibido, porém tem que ser denunciado. Neste ponto, há pouca diferença entre a mulher que não dá conta da criança concebida no seu seio e a outra que procura por um aborto. Ambas são alvo das insinuações de má reputação.

(7) Ordenações Filipinas. Liv. I. Tít. LXXIII, "Dos quadrilheiros”, § 4.

(8) Apesar das Ordenações não contemplarem o aborto criminoso, os juristas consagrados do tempo recomendam que o aborto seja equiparado ao parricídio e, portanto, submetido às mesmas penas (FREIRE, Pascual José Melo. Institutiones Juris Criminalis Lusitani. Liber singularis. Editio quarta in usum, Auditiotii Conimbricensis, juxta primam ann. 1815, sed auctor et emendatior. Conimbricae, ex typis academicis, 1845. IX-14, p.124). Mas esta interpretação é criticada e muitas vezes rejeitada (FERRÃO, Francisco António Fernandes da Silva. Theoria do direito penal applicada ao Codigo Penal portuguez: comparado com o Codigo do Brazil, leis patrias, codigos e leis criminaes dos povos antigos e modernos. Lisboa: Imprensa Nacional, 1857. v. 7, p.81-82). De fato, é significativa a omissão contínua nas leis portuguesas, com relação a aborto e infanticídio, até a modernidade. (SÁ, Isabel Guimarães. Abandono de crianças, infanticídio e aborto na sociedade portuguesa tradicional através os fontes jurídicas. Penélope: fazer e desfazer a história, p. 84-85, 1998). É igualmente significativa a ausência de casos de autoaborto, nos arquivos da justiça colonial (DEL PRIORE, Mary. A árvore e o fruto: um breve ensaio histórico sobre o aborto. Bioética, v. 2, n. 1, p. 43-46, 1994). Os únicos casos registrados são de abortos provocados por maus-tratos causados por terceiros (maridos, donos, vizinhos etc.) (SILVA, Maria Beatriz Nizza da. Sistema de casamento no Brasil colonial. São Paulo: Queiroz, 1984. p. 165-166. (Estudos Brasileiros)). Parece, portanto, que, na ausência de disposições legais expressas, e apesar das recomendações dos juristas consagrados, os juízes do Brasil Colônia fechavam os olhos para as práticas abortivas. 


\section{Um dispositivo liberal}

O aborto é objeto, pela primeira vez, de uma inscrição específica no Código Criminal de 1830, sob o Império. ${ }^{(9)}$ Porém, apenas o ato de fazer abortar uma mulher está penalizado. A mulher que sofreu um aborto não está sujeita ao processo criminal, mesmo que ela tenha solicitado a realização do procedimento. Não se trata de uma omissão do legislador. As manobras abortivas descritas nos livros de medicina da época são muito violentas. $O$ legislador considera que necessariamente causam um dano físico grave à mulher, quer ela tenha consentido ou não ao aborto. ${ }^{(10)}$ Neste dispositivo, o Estado apresenta a mulher como um corpo fraco que deve ser protegido de terceiros mal intencionados. Porém, o Estado adota uma atitude de laissez-faire para com a mulher que toma a decisão de se expor aos perigos do aborto. É claramente um critério liberal - a fronteira do público e do privado - que separa, neste dispositivo, o aborto criminoso do aborto lícito. Por um lado, a presença de terceiros, em torno da mulher grávida, cria uma cena pública na qual o Estado deve intervir. Por outro lado, a mulher que procura um aborto a si mesma se encontra numa esfera privada. Aquela mulher não tem que dar conta à polícia das obrigações que, na mesma época, podem Ihe impor a moral religiosa e a honra familiar para com o ser concebido no seu seio. O legislador apenas lembra o primeiro dos princípios liberais. Isto é, a interdição de prejudicar outrem. Em comparação com o invasivo direito de observação que tinham as autoridades coloniais sobre práticas relacionadas ao aborto, o novo dipositivo inaugura uma autolimitação da curiosidade pública, característica do Estado mínimo tal como concebido no pensamento liberal.

\section{Um dispositivo industrial}

O Código Penal de 1890, sob a primeira República, ataca, em nome de um positivismo militante, as desregulações da higiene pública, supostamente multiplicadas por causa do laxismo do legislador anterior. A nova lei presta voz às revindicações das primeiras faculdades de medicina, que denunciam a proliferação das "casas de maternidade", onde são imoladas em massa as mulheres confiadas aos cuidados das "fazedoras de anjos".(11) O objetivo

(9) Código Criminal do Império do Brasil, arts. 199-200.

(10) A ausência de consentimento apenas constitui uma circunstância agravadora. Idem, art. 199: "Se este crime fôr cometido sem consentimento da mulher: penas — dobradas."

(11) Sobre a continuidade entre as demandas dos médicos e a criação de novos dispositivos jurídicos, durante o século XIX: BRENES, Annayansi Correa. História da parturição no Brasil, século XIX. Cadernos de Saúde Pública, Rio de Janeiro, v. 7, n. 2, p. 148, 1991. Em retorno, cabe à institução médica a missão de denunciar sistematicamente os casos de aborto criminoso descobertos nos serviços de maternidade, criando assim, para todos os efeitos, uma vinculação permanente 
proclamado pelo legislador é a erradicação de tais práticas. Segundo um critério industrial, a avaliação tem como objeto a maestria científica de uma técnica que não deve ser abandonada entre mãos não técnicas. O dispositivo separa, consequentemente, a medicina empírica e científica, as casas de maternidade insalubres e os hospitais modelos, as parteiras incompetentes e os obstetras cautelosos. ${ }^{(12)}$ Trata-se não só de garantir o monopólio das manobras abortivas aos profissionais diplomados das novas faculdades de medicina, porém, sobretudo, de introduzir e consagrar uma técnica clínica e uma ética técnica inéditas. ${ }^{(13)} \mathrm{O}$ Estado não deixa em paz nem a mulher que pretende praticar o aborto em si mesma. Ameaça-a de prisão. A oposição fundamental não passa mais entre aquelas que sofrem um aborto e terceiros acusados de manobras abortivas violentas, mas entre os médicos autorizados a praticá-lo, em virtude de uma competência reconhecida oficialmente, e o conjunto de pessoas ordinárias que produzem anarquia e insalubridade no corpo social por fazer, sem saber fazer, abortos. Por um lado, o aborto legal é a competência exclusiva do médico. Por outro lado, o aborto criminoso é esta mesma competência usurpada e desviada pelo ignorante. A lei opõe o público inculto à instituição médica, e o médico confiável ao charlatão assassino, à comadre sem formação profissional e à mulher grávida, julgada incapaz de tomar cuidado de si.

Em 1940 é elaborado um novo Código Penal e, com relação à questão do aborto, o legislador mantém-se fiel ao critério industrial consagrado pelo código anterior. Limita-se a atualizar o vocabulário jurídico (por exemplo, insere a perífrase "não se pune o aborto" no lugar da fórmula "aborto legal"). Introduz apenas uma modificação notável. O aborto em decorrência de estu-

ao aparelho policial. Por exemplo, Ana Korndörfer cita o Regulamento para o Serviço de Higiene do Estado do Rio Grande do Sul — Decreto n.44, de 2 de abril de 1895: "No caso que constar á autoridade sanitária que em alguma maternidade se praticam abortos criminosos, poderá ella proceder ás pesquizas que entender convenientes e do resultado dará conhecimento ao director de hygiene, para que este transmitta á autoridade policial. Verificado nestas condições, caberá o procedimento criminal que fôr no caso." (citado in KORNDÖRFER, Ana Paula. É melhor prevenir do que curar. a higiene e a saúde nas escolas públicas gaúchas (1893-1928), 2007. Dissertação (Mestrado) - Universidade do Vale do Rio dos Sinos, 2007. p. 100-101). As teses de medicina da época também traduzem a boa vontade dos médicos em colaborar com o sistema judicial e o aparelho policial. VASQUEZ, Georgiane. Mais cruéis do que as próprias feras: aborto e infanticídio nos campos gerais entre o século XIX e o século XX, 2005. Dissertação (Mestrado) - Curso de Pós-Graduação em História, Setor de Ciências Humanas Letras e Artes. Universidade Federal do Paraná, 2005. p. 78-94.

(12) Código Penal dos Estados Unidos do Brasil. "Dos crimes contra a segurança e a vida da pessoa". Arts. 300-302.

(13) A questão do aborto é central no processo de profissionalização da "medicina das mulheres" entre o final do século XIX e o início do século XX. (ROHDEN, Fabíola. A arte de enganar a natureza: contracepção, aborto e infanticídio no início do século XX. Rio de Janeiro: Ed. FIOCRUZ, 2003. 246 p. (Coleção História e Saúde)). Concomitantemente, há, neste período, uma desvalorização das comadres e parteiras, acusadas de praticar abortos em grande escala (CARELLI, Sandra da Silva. De comadres a "faiseuses d'anges": o ofício de parteira nos periódicos rio-grandenses do final do século XIX e das primeiras décadas do século XX no Rio Grande do Sul. Ciências \& Letras, Porto Alegre, n. 41, p. 119-150, 2001). 
pro acrescenta-se doravante ao aborto terapêutico, como aborto lícito. ${ }^{(14)}$ Porém, na ausência de serviços especializados, não se podem agenciar os pedidos das mulheres protegidas pela lei. Portanto, durante mais de um século, tudo acontece como se fosse o mesmo critério industrial que, fortalecendo a posição do médico, determinava a permissibilidade do aborto.

\section{A configuração atual}

Tornam-se possíveis novas políticas e experimentações em relação à questão do aborto, a partir do final dos anos 1980, com o retorno à democracia e graças aos esforços dos movimentos feministas ${ }^{(15)}$. Completada por legislações locais e normas técnicas do Ministério da Saúde, a lei penal de 1940 , ainda vigente, serve a uma nova formalidade jurídica, visando a novos objetivos normativos. O controle policial do aborto cede lugar lentamente a um novo dispositivo, hoje implantado em cerca de 56 hospitais da rede pública, distribuídos em aproximadamente 40 cidades do país. ${ }^{(16)}$

O dispositivo organiza o acesso limitado à interrupção legal de gravidez, nos casos previstos pela lei de 1940. Os critérios de avaliação empregados neste processo parecem mais com aqueles que se encontravam no dispositivo liberal. Porém, o dispositivo atual herdou algumas características do dispositivo industrial. Trata-se de um dispositvo composto, lançando mão de critérios de exigência plurais. Como no dispositivo liberal, a paciente é concebida como um ser vulnerável. Mas o sofrimento feminino é doravante objeto de uma terapêutica, ao invés de uma reparação judicial. Psicólogas e assistentes sociais auxiliam a paciente em todas as etapas. No entanto, como no dispositivo industrial, a realização do aborto é de competência exclusiva do médico. Em compensação, o início do procedimento é devolvido à iniciativa da paciente. Seu pedido de aborto pode ser negado, mas não pode ser praticado sem seu consentimento esclarecido. Ainda que a equipe médica decida de modo soberano pela realização do aborto, tal privilégio não deve resultar, em teoria, numa assimetria permanente. Ao contrário, o desnível inicial deve favorecer uma restituição de autonomia em favor da paciente, ao final do processo. Eis o benefício principal objetivado pelo dispositivo. A expulsão do produto da concepção constitui apenas uma etapa intermediária. Neste sentido, um espaço signi-

(14) Contudo, pode-se dizer, sem forçar demais a realidade, que esta modificação apenas moderniza e amplia uma clausa de mitigação que já existia para as mulheres que procuravam um aborto "para ocultar a desonra pessoal". Código Penal dos Estados Unidos do Brasil, art. 301.

(15) Fizemos um estudo sintético do processo de implementação dos serviços de aborto previsto por lei em um artigo submetido à Revista do CES (Coimbra). CASTELBAJAC, Matthieu de. Governar o aborto com as normas. Transformação das políticas de aborto no Brasil desde o final dos anos 80, 2009.

(16) TALIB, Rosângela; CITELI, Maria Teresa. Serviços de aborto legal em hospitais públicos brasileiros (1989-2004): dossiê. Católicas pelo Direito de Decidir. São Paulo, 2005. 
ficativo é proporcionado para informar a paciente dos seus direitos, dos métodos contraceptivos e dos cudidados sobre a sua sexualidade.

\section{FIGURAS DA RESPONSABILIDADE}

Temos criticado a ideia de uma história jurídica motivada desde sempre com uma vontade invariável de reprimir o aborto. Da mesma forma, poderíamos interrogar o personagem feminino unidimensional apresentado pela hipótese repressiva. Este personagem aparece como uma criatura sempre alienada. Tal imagem não concorda com a diversidade de retratos descritos acima: sexo dissimulador num dispositivo doméstico; indivíduo vulnerável, mas autônomo num dispositivo liberal; paciente em perigo no dispositivo industrial. Não são retratos lisonjeiros. No entanto, o personagem feminino, no dispositivo industrial e no dispositivo atual, mesmo que reduzido a uma caricatura de incompetência, vê-se em compensação creditado de uma vontade e, portanto, pela primeira vez, responsabilizado penalmente por uma ação que vem sendo constituída como sua. ${ }^{(17)}$

\section{A criminalização das mulheres}

Por que razão as mulheres que abortam são jogadas sob o regime de leis punitivas a partir de 1890 ? É tentador evocar o peso de um ethos nacional patriarcal e androcêntrico. Contudo, esta intuição não é satisfatória. Já temos observado que antes desta data nenhuma responsabilidade é atribuída àquelas que procuram um aborto solitário. Se a criminalização das mulheres, no final do século XIX, parece concordar com a ideia de uma cultura opressiva para com as mulheres, o longo período durante o qual elas não são incomodadas pela lei torna-se incompreensível sob este ângulo. Como é possível que os períodos do Brasil-Colônia e do Império, durante os quais construções políticas muito tradicionais ordenam a vida social, sejam marcados neste ponto por uma dominação masculina menos rude e menos visível?

Estas observações devem restituir a descontinuidade radical da nova formalidade jurídica que, de 1890 em diante, faz servir o questionamento das mulheres a uma reorientação punitiva. A análise em termos de cultura

(17) Fabiana Rodrigues destaca aquela figura feminina paradoxal, "marcada por sua não existência calcada na ideia de indivíduo e, assim, estando referida às figuras masculinas que, de alguma forma, se encontram ao seu redor - como pai, marido, tio, irmão, etc. — e por vezes, (...) marcada por sua existência definitivamente individual, quando esta se encontra criminalizada por um crime que já tem como tipo criminológico passível de cometê-lo uma mulher (aborto e infanticídio)". RODRIGUES, Fabiana Cardoso Malha. A criminalização das mulheres: aborto e infanticídio no direito na passagem à modernidade no Brasil, 1890-1916. Diálogos, Maringá, v. 9, n. 2, p. 233, 2006. 
dissolve o problema de antemão por supor que a vontade de repressão é sempre "já presente". Tomando a repressão como um dado, sem considerar as condições pragmáticas que a tornam possível, esta análise oculta a descontinuidade prática e a mudança de lógica que acompanha a centralização súbita dos dispositivos penais em torno da mulher que procura um aborto. Ora, a questão pertinente é justamente determinar como um crime considerado por muito tempo isento de qualquer implicação feminina pôde tornar-se um crime sexualmente diferenciado - até mesmo um crime feminino por excelência.

Ao contrário da ideia que um ethos nacional profundamente patriarcal deixaria pensar, devemos observar que a nova centralidade da mulher no dispositivo jurídico é inicialmente rejeitada pelos juristas brasileiros. Percebem nela uma importação selvagem da doutrina do direito italiano. Pois, até então, a doutrina majoritária considerava tanto o autoaborto, como o suicídio, crimes sem vítimas. Testemunhas desta reação são as observações de João Vieira de Araujo, jurista comissionado para elaborar um projeto de reforma do Código de 1890, quase imediatamente após sua promulgação, em razão de suas numerosas imperfeições:

O capitulo relativo ao aborto é um dos mais deffeituosos do novo codigo (...). Nós, que desde 1830, alcançamos aquelle desideratum não punindo o aborto procurado pela mulher, não devemos voltar atraz, quando tudo leva a crer que os outros codigos riscarão a sua sancção penal nesse ponto. A co-relação social, economica e juridica do aborto, infanticidio e suicidio conduz naturalmente, sinão a isenta-los da pena, abaixar esta nos casos puniveis. ${ }^{(18)}$

Este comentário é muito instrutivo. O jurista absolve a mulher que realizou um aborto, em nome das determinações sociológicas que a fizeram agir. A nova lei penal, desconsiderando as leis sociais, ignora que a mulher incriminada é vítima de uma certa forma de anomia. A reação do jurista revela, por contraste, o novo paradigma presente no Código de 1890. Em realidade, o legislador não quer saber se a mulher incriminada é moralmente culpada ou se uma causalidade sociológica influenciou sua ação. O objetivo da lei é simplesmente retroceder até chegar à primeira pessoa que decidiu a ação criminosa. Em termos de lógica, trata-se de identificar o agente principal.

Porém, como compreender essa mudança? Considerando a diversificação dos casos previstos pelo Código de 1890, Georgiane Vazquez sugere que a criminalização das mulheres se integra a um projeto do legislador de punir o maior número de pessoas implicadas na realização do aborto, para erradicar as práticas abortivas. ${ }^{(19)}$ Uma severidade tão abragente responde à perturbação da opinião pública, bem documentada por Sandra Carelli, e

(18) Projeto n. 250 de 21 de Agosto de 1893".

(19) VASQUEZ, Georgiane. op. cit., p. 103. 
suscitada pela descoberta de fetos abortivos "em cubos, em poços de esgoto, boiando em rios e riachos, em sarjetas, em terrenos baldios, embrulhados em papéis, estraçalhados por animais". ${ }^{(20)}$ A criminalização das mulheres permitiu satisfazer a vendeta popular que exigia que lhe fossem designados os culpados.

A hipótese que privilegiamos encontra-se a meio caminho destas duas ideias. A incriminação das mulheres responde a uma exigência de imputabilidade. Não se trata apenas de designar um culpado. Trata-se de identificar um sujeito voluntário. O juiz doravante coloca a pergunta: Quem? No entanto, faz esta pergunta em relação à questão do consentimento e da vontade da mulher. Consentir não é mais uma circunstância, como no Código de 1830, mas um ato de vontade. E é neste ato que doravente recai o interesse da lei. De 1890 em diante, consentir com o aborto, procurá-lo para si ou para outra mulher com seu consentimento são consideradas situações análogas. Por meio da criminalização das mulheres e da feminilização do aborto criminoso, move-se permanentemente a atenção do avaliador, da realização material do aborto, para o ato de vontade que a encetou. ${ }^{(21)}$

\section{Consentimento e autonomia}

Por correspondência, este deslocamento instala as condições de possibilidade de uma avaliação do aborto permitido que se reduz também a determinar um ato de vontade. Este ato intencional e individual é formalizado no dispositivo atual, não por intermédio de uma atribuição exterior (isto é, o veredito do tribunal), mas por meio de um termo de consentimento esclarecido que deve ser assinado pela própria candidata a um aborto não punível, para que seu pedido seja homologado. ${ }^{(22)} \mathrm{O}$ referido documento inclui as informações que devem ser conhecidas pela paciente, para garantir a validade da sua escolha. ${ }^{(23)}$ Além das informações julgadas úteis pelo hospital, contém uma declaração expressa (redigida em primeira pessoa), indicando a decisão livre e consciente da paciente. Esta declaração torna-se efetiva com a assinatura da paciente.

(20) CARELLI, Sandra da Silva. Estratégias da imprensa sul-rio-grandense na construção da ideia do aborto provocado como uma prática nociva à sociedade. Segundas Jornadas de História Regional Comparada. Outubro 2005, p. 4. Disponível em: <http://www.fee.tche.br/sitefee/download/jornadas/ 2/h13-01.pdf>.

(21) Torna-se doravante acessório saber se as manobras abortivas produzirão efeitos. O Código de 1890 afirma: "Provocar aborto, haja ou não expulsão do fruto da concepção". Código Penal dos Estados Unidos do Brasil, art. 300.

(22) O consentimento da paciente não é necessário para o aborto terapêutico, caso a urgência de salvar a vida da paciente não permitisse.Todavia, é necessário informar a paciente dos seus direitos se ela é exposta a um risco numa fase ulterior da gravidez. Seu consentimento é então recomendado para que a intervenção seja programada. FAUNDES, Anibal; TORRES, José Henrique Rodrigues. O abortamento por risco de vida da mãe. In: CATÓLICAS pelo direito de decidir. Aborto legal: implicações éticas e religiosas. São Paulo: Edições Loyola, 2002. p. 156.

(23) O formato atual foi definido pelo Ministério da Saúde. Portaria n. 1.508, 02/09/2005. 
O termo de consentimento materializa a decisão da paciente e operacionaliza a relação médica entre ela e os profissionais da saúde envolvidos. De modo que uma mulher estuprada ou em perigo de morte colocar-se-ia em situação faltosa, do ponto de vista da lei, caso procurasse um aborto fora do quadro hospitalar. De forma análoga, o médico que praticasse um aborto em uma mulher que sofreu um estupro, a pedido dos pais da vítima, por exemplo, sem o consentimento daquela que é considerada o agente principal pela lei, agiria na mais completa ilegalidade, pois teria afastado uma competência reconhecida a sua paciente. Assim, para realizar um aborto "legal", é preciso uma dupla transferência de competências, do médico à paciente e da paciente ao médico. Por um lado, o médico deve agir em nome de sua paciente, munido do seu consentimento esclarecido. Por outro, a paciente só pode concretizar sua escolha por procuração, depois de ter autorizado o médico a realizar o procedimento para ela. Esta divisão do trabalho implica a complementaridade das competências e das responsabilidades compartiIhadas entre o médico e sua paciente - e eis precisamente a condição de um aborto nas regras da arte médica. A decisão individual da paciente tem que estar associada a uma colaboração com profissionais da saúde, que revindicam uma certa ética profissional, garantindo deste modo que o aborto seja realizado, não por motivos potencialmente arbitrários, mas por razões explicítas e consonantes com os princípios gerais definidos pela lei.

A complementaridade das competências e das responsabilidades entre a paciente e o médico redistribui, entre eles, duas modalidades do "reconhecimento de responsabilidade", para acompanhar Paul Ricoeur, ou seja, a modalidade do "eu posso falar" e a do "eu posso fazer". (24) A continuidade genética entre estas duas modalidades é reportada, por meio do termo de consentimento, sobre as responsabilidades diferenciadas, porém complementares, que são reconhecidas ao médico e à paciente. A anterioridade lógica atribuída ao poder performativo da palavra ("eu posso falar") — já que o ato de assinar o consentimento vale como tal - autoriza, além disso, a competência técnica (o "eu posso fazer") do médico. Em outras palavras, é a paciente que, tendo exprimido sua vontade, faz fazer ao médico o aborto. É ela o sujeito reconhecido da ação. Este sujeito apresenta-se como um indivíduo vulnerável (ela é acompanhada por uma equipe de profissionais da saúde que agem em seu nome) contudo responsável (ela só suporta as consequências do procedimento, que conhece e para as quais assinou um consetimento esclarecido). Entretanto, a conformação a este procedimento gera enorme pressão sobre a paciente, transformando sua intimidade em objeto ajustado por contrato, formalizado como escolha individual e exposto ao julgamento público.

(24) RICOEUR, Paul. Parcours de la reconnaissance: trois études. Édition de poche. Paris: Gallimard, 2005. p.155 et seq. A relação médico-paciente é o objeto de um tratamento mais específico em outras publicações do filósofo: RICOEUR, Paul. Les trois niveaux du jugement médical. Esprit, p. 21-32, Dec. 1996. 


\section{AS “HIPÓTESES” DO ABORTO PREVISTO POR LEI}

Aborto não é considerado crime, de acordo com o Código Penal em vigor, em duas "hipóteses". ${ }^{(25)}$ Os juristas costumam chamar a primeira hipótese de "aborto necessário" ou "aborto terapêutico". O aborto é praticado neste caso para salvar a vida da paciente, caso não haja outro meio disponível. A segunda hipótese é mais frequentemente chamada de "aborto sentimental" e às vezes de "aborto humanitário", quando o aborto destruiu o resultado de um estupro. No primeiro caso, o caráter criminoso de aborto está colocado entre parênteses, como o homicídio cometido em situação de legítima defesa, por exemplo. No segundo caso, o aborto é concedido por compaixão. É injusto forçar a paciente a suportar o suplício de uma gravidez brutalmente imposta por seu agressor. ${ }^{(26)}$ Embora a formulação destes preceitos permissivos ("Não se pune o aborto...") manifeste a relutância do legislador de 1940 em perenizá-los, tornaram-nos, para todos os efeitos, direitos autênticos a partir do final dos anos 1980, quando normas locais e ministeriais começaram a ser publicadas para organizar o processo de implantação dos serviços especializados, em hospitais da rede pública. ${ }^{(27)}$

Cada hipótese é, em teoria, necessária e suficiente para escapar das proibições legais que fecham o acesso ao aborto lícito. Podemos notar imediatamente que as justificativas que sustentam as três hipóteses não têm muito a ver com os argumentos aos quais a filosofia moral se refere geralmente. ${ }^{(28)}$ A maior parte da discussão filosófica contemporânea concentra-se na questão de determinar se deve ser reconhecida ao "feto" a dignidade de pessoa, em particular desde a publicação do famoso ensaio de Judith Jarvis Thomson, no qual a filósofa argumentou que o aborto é fundado moralmente, mesmo no caso de que o feto seja considerado como uma pessoa a quem a vida será retirada. ${ }^{(29)}$ Porém, a discussão jurídica no Brasil contornou cui-

(25) Código Penal do Brasil, art. 128.

(26) Sobre essas justificativas, na literatura jurídica: BALBINOT, Rachelle. Discutir o aborto: um desafio ético. 2002. Dissertação (Mestrado) — Faculdade de Direito, Universidade Federal de Santa Catarina, 2002. p. 36. Para a mesma discussão do ponto de vista da ética médica: DALLARI, Sueli Gandolfi. Aborto: um problema ético da saúde pública. Bioética, v. 2, n. 1, p. 37-41, 1994.

(27) A jurisprudência estabeleceu mais recentemente uma terceira hipótese. O "aborto por malformação fetal incompatível com a vida extrauterina" - também chamado, de maneira polêmica, de "aborto seletivo" ou de "aborto eugênico" - intervém após o diagnóstico pré-natal à demanda da gestante, se fosse descoberto por meio da ecografia que o nascituro não é viável, por causa de uma malformação letal. A interrupção de gravidez está autorizada neste caso para evitar àquela que não será mãe a tortura de um parto fúnebre. Deve-se destacar que o procedimento não autoriza a supressão do produto da concepção sob o pretexto de que faria um humano imperfeito. Proporciona simplesmente a oportunidade de evitar um parto inútil à mulher. No entanto, o espectro do eugenismo é frequentemente invocado por juízes de má-fé para negar os pedidos de aborto das pacientes elegíveis. DINIZ, Debora. Quem autoriza o aborto seletivo no Brasil? Médicos, promotores e juízes em cena. Physis: Revista de Saúde Coletiva, v. 13, n. 2, p. 13-34, 2003.

(28) Para uma discussão detalhada das justificativas imaginadas pelos filósofos dessa tradição: BOLTANSKI, Luc. op. cit., p. 235 et seq.

(29) THOMSON, Judith Jarvis. A defense of abortion. Philosophy and Public Affairs, n. 1. v. 1, p. 47-66, 1971. 
dadosamente este problema. A legislação civil achou uma fórmula de compromisso que conseguiu a proeza de negar a pessoalidade jurídica do feto e ao mesmo tempo reconhecer os direitos que serão seus quando será parte da comunidade dos vivos: "A personalidade civil do homem começa do nascimento com vida; mas a lei põe a salvo, desde a concepção, os direitos do nascituro."(30) É preciso observar que a segunda frase designa exclusivamente os direitos sucessórios e patrimoniais que a criança poderá reclamar (o que implica um dever de garantia da parte do Estado), desde que cumpra a condição formulada na primeira frase: ou seja, com a condição puramente factual (o que não implica nenhum dever do Estado) de nascer com vida. Não se trata de um "direito à vida", como sugerem alguns juristas, que pretendem fragilizar a juridicidade das hipóteses de aborto não punível. ${ }^{(31)}$

Em realidade, os preceitos permissivos formulados pelo legislador descrevem apenas as circunstâncias do procedimento em questão: quem faz o que, onde, por que meios, por que, como e quando (reproduzindo aproximadamente uma fórmula clássica). Quem faz o quê? A lei encena uma relação operativa (resultando na execução de uma competência técnica do médico) entre um profissional da saúde e uma mulher grávida, sem jamais fazer referência ao produto da concepção. Onde? Supõe um lugar, o hospital, onde o médico exerce regularmente sua profissão. Por que meio ? Supõe outrossim que os meios empregados sejam mestrados, o que justifica o monopólio médico. Por quê? Visa a finalidades que dizem respeito ao bem-estar físico (aborto terapêutico) e psíquico (aborto sentimental) da paciente. Como? Necessita que o procedimento seja praticado com cautela, pois o médico pode eventualmente ser punido por imperícia. Quando? A lei autoriza o aborto quando não há outro meio de salvar a vida da paciente, ou em decorrência do seu estupro.

A lei não define um comportamento, mas uma situação. Podemos contrastar esta ideia com um argumento filosófico às vezes evocado contra o aborto, e que parece o negativo daquele defendido por Judith Jarvis Thomson, que já foi citado. O argumento é de Elizabeth Anscombe. Pode se resumir assim: fazer aborto é mal, mesmo no caso de que o feto (ainda) não seja uma pessoa, pois é tratar como "matéria descartável" (disposable material) algo que, sem ser uma pessoa, pertence ao humano. Como seria chocante que este "algo" fosse reduzido a uma mercadoria para ser comercializado, suprimi-lo "por comodidade pessoal" tem que ser imoral.(32) Um tal argumento acaba dizendo que fazer aborto é demonstrar um comportamento indigno (e portanto censurável), qual seja a forma escolhida para abortar.

(30) BRASIL, Novo Código Civil. Parte geral I, I, I, art.2.

(31) Existe uma tendência a buscar neste artigo uma razão jurídica para deslegitimar a política de extensão do aborto previsto por lei, mas, é recente, sem bases sérias e contrária à doutrina majoritária. Sobre esta questão: BALBINOT, Rachelle. op. cit., p. 65 et seq.

(32) ANSCOMBE, Gertrude Elizabeth Margaret. The dignity of the human being. In: HUMAN life, action and ethics: essays by G.E.M. Anscombe. Exeter: Imprint Academic, 2005. p. 67-76. 
Pelo contrário, o jurista considera apenas de qual forma a ação é levada. A limitar-se ao texto da lei, é permitido o aborto conforme algumas exigências nitidamente esquematizadas, enquanto é criminosa a ação que não corresponde às formas previstas. Do ponto de vista jurídico, só pode acontecer de duas coisas, uma: ou a ação convém ao formato definido pelo Direito, ou é crime. Esta alternativa ensina-nos, porque os juristas chamam de "hipóteses", os preceitos permissivos previstos por lei. Cada preceito toma a forma de um "se e só se - então". A avaliação jurídica dá-se com essas hipóteses em formato genérico, restringindo o horizonte da avaliação a um pequeno número de requisitos. Assim, se a situação associa médico e paciente, se a intervenção é realizada em hospital, se os meios empregados são mestrados, se as finalidades perseguidas são legítimas, se o procedimento é praticado com cautela e se ocorre quando não há outro meio de salvar a vida da paciente ou em decorrência do seu estupro - então o aborto é, propriamente dito, um aborto "em devida forma", e é legal.

Desta forma, a lei delimita um modo de usar, uma manual de instruções, para fazer um aborto como se deve. Não se trata apenas de categorias a serem utilizadas pelo julgamento de Direito. São referências convencionais para a ação, contempladas pelos julgamentos ordinários que acompanham a realização do aborto previsto por lei na situação concreta, por pessoas que não são profissionais do Direito. Essas pessoas se encontram frente a casos que, por serem provenientes de situações muito íntimas e por definição violentas (estupro, perigo de morte), são pouco preparados para passar por uma avaliação pública, ou seja, para serem submetidos à prova de um julgamento de legalidade. Ora, para que as formalidades da lei possam se aplicar à situação concreta, é requerido das pessoas que se conformem às exigências de uma ação justificável (sujeita a justificativas) e justiciável (que pode eventualmente ser objeto da justiça). E eis uma dinâmica cuja compreensão só se torna possível com a condição de o observador se mostrar atento às formas gerais agenciadas por atores que não são juristas, mas que se esforçam em agir legalmente, ou seja, na devida forma. ${ }^{(33)}$

\section{CONSIDERAÇÕES FINAIS}

Afinal, estamos em condições de propor uma descrição do aborto legal no Brasil contemporâneo. Este apanhado não rompe com as definições usuais e particulares do jurista ou do médico para substituí-las com uma definição definitiva que teria o privilégio da objetivação sociológica. Nosso propósito

(33) Para um estudo mais completo deste trabalho: CASTELBAJAC, Matthieu de. A pragmática do sofrimento nos dispositivos de aborto previsto por lei no Brasil. Texto apresentado no Congresso Luso-afro brasileiro de Ciências Sociais. Sociedades desiguais e paradigmas em confronto. Universidade do Minho, Instituto de Ciências Sociais, Braga. Org, 2009. 
foi simplesmente chamar a atenção a uma parte dos apoios convencionais e das referências formais que equipam a realização do aborto não punível. Ao invés de uma definição conceitual, ganhamos um modo de usar. Pois, fazer um aborto no quadro da lei, é fazer uso de formas que preparam o terreno para os atores. Resumindo, eis os traços gerais do aborto legal. Em primeiro lugar, é separado do aborto criminoso por uma linha tênue. Apresentamos a diferenciação contínua das duas categorias, a centralidade recente do indivíduo feminino na determinação jurídica do aborto e os conceitos permissivos da lei vigente. Atualmente, a distinção entre o permitido e o proibido está avaliada graças a uma fórmula de caráter misto, com uma forte orientação liberal, que enfatiza uma figura sofredora, porém responsável da mulher que pode pedir o aborto previsto por lei. No dispositivo atual, "ela" é o sujeito reconhecido da ação, ainda que seja o médico que execute a operação cirúrgica ou que lhe indique o remédio abortivo. Contudo, sua hospitalização, isto é, a realização do seu pedido dentro de um quadro médico regular, permanece uma condição necessária para que o aborto seja feito de maneira legal. Contudo, mais do que uma intervenção hospitalar, o aborto previsto por lei apresenta-se como um projeto de autonomia mais amplo, elaborado por uma deliberação ética feita a muitas vozes. Para nosso estudo, o fato principal é que esta deliberação polifônica e este projeto de autonomia engajam a mulher que pede um aborto no quadro da lei a se tornar paciente informada e agente responsável por uma escolha que será qualificada, portanto, como sua escolha pessoal.

\section{REFERÊNCIAS BIBLIOGRÁFICAS}

ANSCOMBE, Gertrude Elizabeth Margaret. The dignity of the human being. In: HUMAN life, action and ethics: essays by G.E.M. Anscombe. Exeter: Imprint Academic, 2005. p. 67-76.

BALBINOT, Rachelle. Discutir o aborto: um desafio ético. 2002. Dissertação (Mestrado) - Faculdade de Direito, Universidade Federal de Santa Catarina, 2002.

BRENES, Annayansi Correa. História da parturição no Brasil, século XIX. Cadernos de Saúde Pública, Rio de Janeiro, v. 7, n. 2, p. 135-149, 1991.

BOLTANSKI, Luc; THEVENOT, Laurent. De la justification: les économies de la grandeur. Paris: Gallimard, 1991.

CARELLI, Sandra da Silva. De comadres a "faiseuses d'anges": o ofício de parteira nos periódicos rio-grandenses do final do século XIX e das primeiras décadas do século XX no Rio Grande do Sul. Ciências \& Letras, Porto Alegre, n. 41, p. 119-150, 2001. 
CARELLI, Sandra da Silva. Estratégias da imprensa sul-rio-grandense na construção da ideia do aborto provocado como uma prática nociva à sociedade. Segundas Jornadas de História Regional Comparada. Outubro 2005. Disponível em: <http://www.fee.tche.br/sitefee/download/jornadas/ 2/h13-01.pdf>.

CASTELBAJAC, Matthieu de. Se détacher sans heurts: étude des dispositifs d'interruption légale de grossesse dans le Brésil contemporain. 2008. Dissertação (Mestrado) - Institut d'Études Politiques de Paris, École Doctorale de Sciences Po, 2008.

CASTELBAJAC, Matthieu de. A pragmática do sofrimento nos dispositivos de aborto previsto por lei no Brasil. Texto apresentado no Congresso Luso-afro brasileiro de Ciências Sociais. Sociedades desiguais e paradigmas em confronto. Universidade do Minho, Instituto de Ciências Sociais, Braga. Org, 2009.

DALLARI, Sueli Gandolfi. Aborto: um problema ético da saúde pública. Bioética, v. 2, n. 1, p. 37-41, 1994.

DEL PRIORE, Mary. A árvore e o fruto: um breve ensaio histórico sobre o aborto. Bioética, v. 2, n. 1, p. 43-51, 1994.

DINIZ, Débora. Quem autoriza o aborto seletivo no Brasil? Médicos, promotores e juízes em cena. Physis: revista de saúde coletiva, v. 13, n. 2, p. 13-34, 2003.

FAUNDES, Aníbal, BAZELATTO, José. O drama do aborto: em busca de um consenso. Campinas: Komedi, 2004. 303 p.

FAUNDES, Anibal; TORRES, José Henrique Rodrigues. O abortamento por risco de vida da mãe. In: CATÓLICAS pelo direito de decidir. Aborto legal: implicações éticas e religiosas. São Paulo: Edições Loyola, 2002. p. 147-158.

FERRÃO, Francisco António Fernandes da Silva. Theoria do direito penal applicada ao Codigo penal portuguez: comparado com o Codigo do Brazil, leis patrias, codigos e leis criminaes dos povos antigos e modernos. Lisboa: Imprensa Nacional, 1857. v. 7, 237 p.

FOUCAULT, Michel. Histoire de la sexualité l: la volonté de savoir. Paris: Gallimard, 1976. 271 p.

FREIRE, Pascual José Melo. Institutiones Juris Criminalis Lusitani. Liber singularis. Editio quarta in usum, Auditiotii Conimbricensis, juxta primam ann. 1815, sed auctor et emendatior. Conimbricae, ex typis academicis, 1845.

KORNDÖRFER, Ana Paula. É melhor prevenir do que curar. a higiene e a saúde nas escolas públicas gaúchas (1893-1928). 2007. Dissertação (Mestrado) - Universidade do Vale do Rio dos Sinos, 2007. 
MIRABETE, Julio Fabrini. Manual de direito penal: parte especial. São Paulo: Atlas, 2003.

MOTA, Fabio Reis. Deslocamentos, movimentos e engajamentos: as formas plurais da ação humana na perspectiva de Laurent Thévenot. Revista Antropolítica, Niterói, n. 23, 2008.

RICOEUR, Paul. Parcours de la reconnaissance: trois études. Édition de poche. Paris: Gallimard, 2005. 429 p. . Les trois niveaux du jugement médical. Esprit, p. 21-32, Dec. 1996.

RODRIGUES, Fabiana Cardoso Malha. A criminalização das mulheres: aborto e infanticídio no direito na passagem à modernidade no Brasil, 1890-1916. Diálogos, Maringá, v. 9, n. 2, p. 233-238, 2006.

ROHDEN, Fabíola. A arte de enganar a natureza: contracepção, aborto e infanticídio no início do século XX. Rio de Janeiro: Fiocruz, 2003. 246 p. (Coleção História e Saúde).

SÁ, Isabel Guimarães. Abandono de crianças, infanticídio e aborto na sociedade portuguesa tradicional através os fontes jurídicas. Penélope: fazer e desfazer a história, p. 76-89, 1998.

SILVA, Maria Beatriz Nizza da. Sistema de casamento no Brasil colonial. São Paulo: Queiroz, 1984. 264 p. (Estudos Brasileiros).

TALIB, Rosângela; CITELI, Maria Teresa. Serviços de aborto legal em hospitais públicos brasileiros (1989-2004): dossiê. Católicas pelo Direito de Decidir, São Paulo, 2005.

THEVENOT, Laurent. Les investissements de forme. In: THÉVENOT, Laurent (Ed.). Conventions économiques. Paris: Presses Universitaires de France, 1986. (Cahiers de Centre d'Étude de l'Emploi).

. L'action au pluriel: Sociologie des régimes d'engagement. Paris:

La Découverte, 2006. 310p.

THOMSON, Judith Jarvis. A defense of abortion. Philosophy and Public Affairs, n. 1. v. 1, p. 47-66, 1971.

VASQUEZ, Georgiane. Mais cruéis do que as próprias feras: aborto e infanticídio nos campos gerais entre o século XIX e o século XX. 2005. Dissertação (Mestrado) - Curso de Pós-Graduação em História, Setor de Ciências Humanas, Letras e Artes. Universidade Federal do Paraná, 2005. 